\title{
The impact of the COVID-19 pandemic on perceived access to health care and preferences for health care provision in individuals (being) treated for breast cancer
}

\author{
Dieuwke R. Mink van der Molen ${ }^{1}$ (D) Claudia A. Bargon ${ }^{1,2} \cdot$ Marilot C. T. Batenburg $^{1} \cdot$ Lilianne E. van Stam ${ }^{1}$. \\ Iris E. van Dam ${ }^{3} \cdot$ Inge O. Baas ${ }^{4} \cdot$ Miranda F. Ernst $^{5}$. Wiesje Maarse ${ }^{6} \cdot$ Maartje Sier $^{7}$. Ernst J. P. Schoenmaeckers ${ }^{8}$. \\ Thijs van Dalen ${ }^{9} \cdot$ Rhodé M. Bijlsma $^{4} \cdot$ Annemiek Doeksen $^{2} \cdot$ Femke van der Leij $^{3} \cdot$ Danny A. Young-Afat $^{10}$. \\ Helena M. Verkooijen ${ }^{1,11}$ on behalf of UMBRELLA study group
}

Received: 9 September 2021 / Accepted: 14 November 2021 / Published online: 1 December 2021

(c) The Author(s), under exclusive licence to Springer Science+Business Media, LLC, part of Springer Nature 2022

\begin{abstract}
Purpose To evaluate perceived access to health care and preferences for health care provision among patients (being) treated for breast cancer during the COVID-19 pandemic.

Methods Longitudinal study within the prospective, multicenter UMBRELLA cohort of patients (being) treated for breast cancer. All cohort participants enrolled in UMBRELLA between October 2013 and November 2020 were sent a COVID19-specific survey during the first and second wave of the COVID-19 pandemic, i.e., April 2020 and November 2020, respectively.

Results In total, 1106 (69.3\%) and 822 (50.9\%) cohort participants completed the survey in the first and second wave, respectively. The proportion of patients experiencing that their treatment or follow-up care was affected due to COVID-19 decreased from 28.4\% $(n=198)$ in April 2020 to 14.8\% $(n=103)$ in November 2020. Throughout the pandemic, one or more hospital consultations were postponed in $10.0 \%(n=82)$ of all patients and changed into a teleconsultation in $23.1 \%$ $(n=190)$. The proportion of patients who experienced a higher threshold to contact their general practitioner due to COVID19 decreased from $29.9 \%(n=204)$ in the first wave to $20.8 \%(n=145)$ in the second wave. In-person consultations remained most preferred in $35.2 \%(n=289)$ of all patients. Nearly half of all patients $(48.3 \%, n=396)$ indicated that telehealth would be a useful alternative for in-person consultations in future.

Conclusion Perceived access to health care has improved substantially throughout the pandemic. Digital care is well received by patients (being) treated for breast cancer.
\end{abstract}

Keywords Breast cancer · COVID-19 · Corona virus $\cdot$ SARS-CoV-2 $\cdot$ Pandemic

$\begin{aligned} & \text { Abbreviations } \\ & \text { BMI }\end{aligned}$
$\begin{array}{ll}\text { COVID-19 } & \text { COdy Mass Index } \\ \text { DCIS } & \begin{array}{l}\text { Ductal carcinoma in situ } \\ \text { METC }\end{array} \\ & \text { Medical Ethics Research Com- } \\ \text { mittee (Dutch: Medisch Ethische } & \text { Toetsingscommissie) } \\ \text { Netherlands Cancer Registry }\end{array}$
NCR
$\begin{aligned} & \square \text { Dieuwke R. Mink van der Molen } \\ & \text { D.R.MinkvanderMolen-2@ umcutrecht.nl }\end{aligned}$
$\begin{aligned} & \text { Helena M. Verkooijen } \\ & \text { H.M.Verkooijen@umcutrecht.nl }\end{aligned}$
Extended author information available on the last page of the article

No. Number

SD Standard deviation

SPSS Statistical Package for Social Sciences

UMBRELLA Utrecht cohort for Multiple BREast

cancer intervention studies and Long-term evaLuAtion

UMCU University Medical Center Utrecht

\section{Introduction}

The coronavirus disease 2019 (COVID-19) pandemic and its associated restrictions led to a multitude of challenges for health care systems worldwide. In the Netherlands, the national screening program for breast cancer was halted 
from March 2020 and Dutch guidelines for breast cancer treatment were temporarily adapted to alleviate the burden on the health care system, resulting in postponement and cancelation of breast cancer screening, treatment, and follow-up care [1-4].

In the Netherlands, the incidence of breast cancer diagnoses fell with approximately $35 \%$ during the first months of the COVID-19 pandemic [5, 6]. Moreover, one in three patients reported changes in their cancer care and increased concerns about the consequences of the delay in treatment and perceived barriers in access to health care were observed $[3,7,8]$. All residents in the Netherlands are entitled to a basic health insurance and therefore have access to the Dutch health care system. In order to comply with social distancing guidance during the pandemic, patients were asked to attend hospital appointments alone and in-person hospital appointments were frequently converted to video and telephone consultations [9]. During lockdown in the Netherlands, the use of public transport was limited but allowed for essential travel, such as for hospital appointments. The average distance to a Dutch hospital is only $4.8 \mathrm{~km}$ [10].

The Dutch national screening program for breast cancer was partially resumed from July 2020 onward [4, 11]. Furthermore, transformations within the health care system, such as the implementation of additional safety measures and telehealth (i.e., telephone and video consultations), were paramount to continue breast cancer treatment and follow-up care as much as possible amid the COVID-19 crisis. In light of the magnitude of transformations in breast cancer care since the onset of the COVID-19 pandemic, it is important to monitor the long-term effects of the adaptations in breast cancer care among patients and survivors [7].

The aim of this study was to better understand the impact of the continuing COVID-19 pandemic on perceived access to health care and preferences for health care provision in patients (being) treated for breast cancer and a non-cancer reference population nine months after the onset of the COVID-19 pandemic in the Netherlands.

\section{Materials and methods}

\section{Study design and participants}

The present study was conducted within the prospective, multicenter 'Utrecht cohort for multiple breast cancer intervention studies and long-term evaluation' (UMBRELLA) $[12,13]$. Since 2013, the cohort includes patients with breast cancer referred to the Department of Radiation Oncology of the University Medical Center Utrecht for post-operative radiation therapy. Prior to radiation therapy, patients were consecutively invited for participation in the UMBRELLA cohort. All patients gave informed consent for collection and use of clinical data and PROs through online or paper questionnaires at regular intervals during and after breast cancer treatment (prior to radiation therapy, i.e., after surgery [baseline], after 3 and 6 months, and each six months up to 10 years thereafter) [12]. Patients aged 18 years or older with histologically proven invasive breast cancer or ductal carcinoma in situ (DCIS), adequate understanding of the Dutch language, and no mental impairment were eligible for inclusion. The UMBRELLA study adheres to the Dutch Law on Medical Research Involving Human Subjects (WMO) and the Declaration of Helsinki (version 2013). Ethical approval was obtained from the University Medical Center Utrecht (NL52651.041.15, Medical Ethics Committee 15/165). The UMBRELLA study is registered on clinicaltrials.gov (NCT02839863).

\section{Data collection}

During the first and second wave of the COVID-19 pandemic in the Netherlands (i.e., in April 2020 and November 2020, respectively), all active UMBRELLA cohort participants who were enrolled since October 2013 and consented to fill out online questionnaires were invited to complete an additional COVID-19-specific survey. Participants received the first survey in April 2020 and the second survey in November 2020. A reminder was sent after two weeks in case of no response. Results of the first COVID-19-specific survey were published earlier by Bargon et al. [8].

A reference population was invited to complete all relevant questions of the second COVID-19-specific survey. For this purpose, UMBRELLA participants were asked to invite a relative, friend, and/or neighbor without a history of cancer and within a five-year age range compared to their actual age.

The surveys included COVID-19-specific questions which were developed by our team of clinical experts and epidemiologists to evaluate presence of COVID-19 and to assess the impact of the COVID-19 pandemic on the patients' perceived access to health care, preferences for health care provision, and health care consumption. The surveys included multiple choice questions regarding the (perceived) impact of the COVID-19 pandemic on the patients' current and future treatment or follow-up care, barriers to contact general practitioners or breast cancer physicians, and preferences for digital medical and/or supportive care.

Clinical data, including age at cohort inclusion, highest educational level, pathological T stage (AJCC 7th and 8th edition), type of surgery, and (neo-)adjuvant radiation therapy and systemic treatment, were routinely collected in the context of UMBRELLA or provided by the Netherlands Cancer Registry (NCR) [14]. BMI was based on the last reported weight $(\mathrm{kg})$ and height $(\mathrm{m})$ during follow-up in the UMBRELLA cohort and calculated as $\mathrm{kg} / \mathrm{m}^{2}$. 


\section{Statistical analysis}

Frequencies, proportions, means with standard deviations (SDs) or ranges, and medians with ranges, as appropriate were used to describe patient demographics, clinical characteristics, and results of the COVID-19-specific surveys.

Impact of the COVID-19 pandemic on perceived access to health care and preferences for health care provision between patients receiving active treatment and patients receiving follow-up care were expressed as proportions and compared with Fisher's exact test and Chi-squared test. Active treatment was defined as being treated for breast cancer with endocrine therapy, chemotherapy, immunotherapy, and/or radiation therapy at the time of completing the survey. All reported p-values were 2 -sided and $p$-values $<0.05$ were considered statistically significant. Statistical analyses were performed with IBM Statistical Package for Social Sciences (SPSS) software, version 26 (IBM Corp., Armonk, NY).

\section{Results}

\section{Study population}

During the first wave, 1595 of 3239 UMBRELLA participants received the COVID-19-specific survey, of whom 1106 (69.3\%) responded (Fig. 1). During the second wave, 1614 of 3364 UMBRELLA participants were eligible for the present study and were sent to the COVID-19-specific survey. Of those, 822 (50.9\%) completed the survey. A total of 696 (43.1\%) UMBRELLA participants completed both surveys.

Demographic and clinical characteristics were similar between responders of the first and second COVID-19-specific survey (Table 1). During the first wave, the mean age of responders was 56 (range 24-82) years and median followup time since enrollment in the UMBRELLA cohort was 29 (range 1-78) months. The majority of the responders were treated for stage I breast cancer $(n=641,58.0 \%)$ and $31.6 \%$

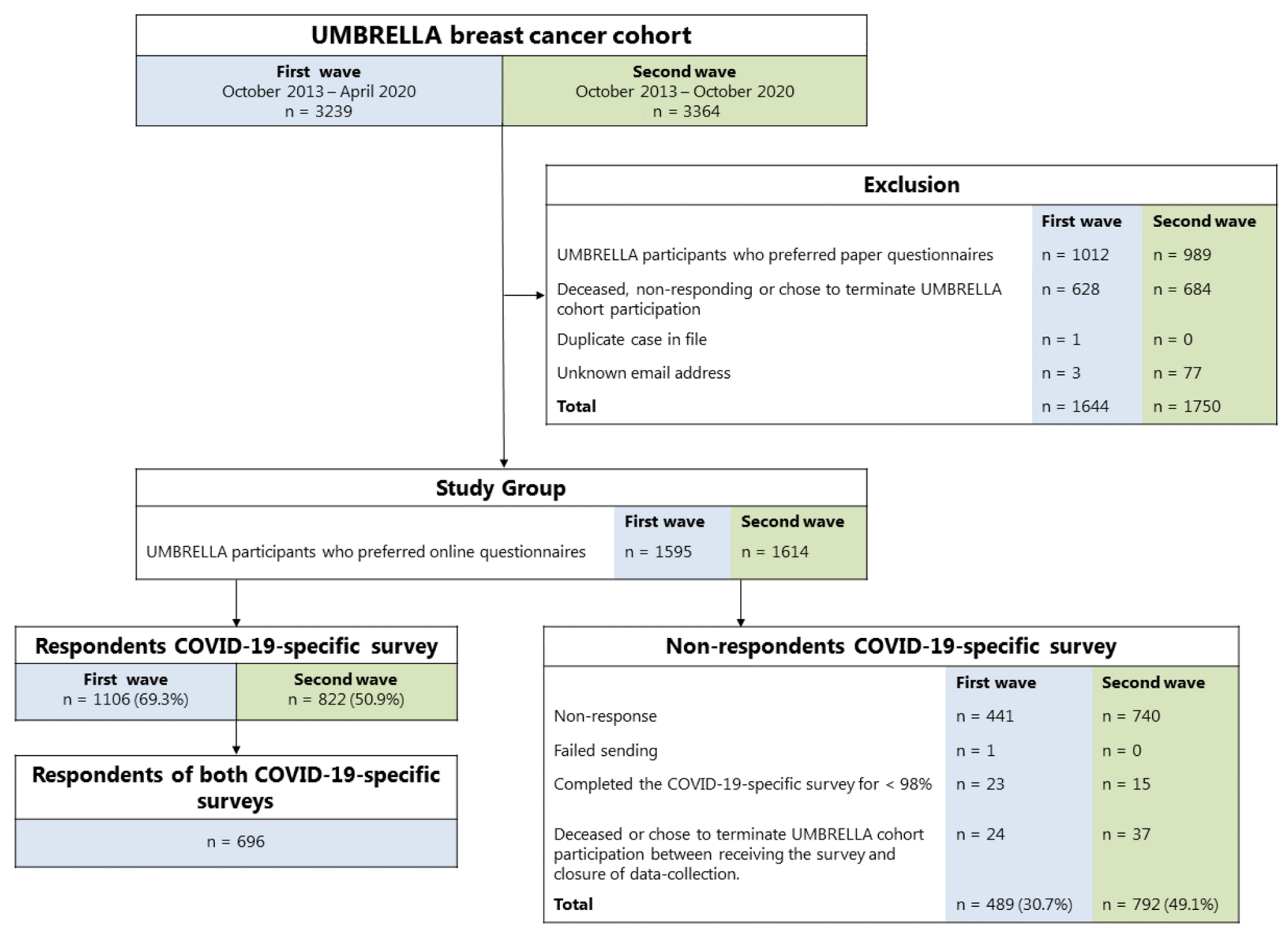

Fig. 1 Flowchart of breast cancer patients in the UMBRELLA cohort receiving the COVID-19-specific survey during the first and the second wave of the COVID-19 pandemic 
Table 1 Baseline characteristics of responders of the COVID19-specific surveys compared to a reference population during the first and the second wave of the COVID-19 pandemic, i.e., April 2020 and November 2020, respectively

\begin{tabular}{|c|c|c|c|c|c|c|c|c|}
\hline \multirow{2}{*}{ Patient characteristics } & \multicolumn{2}{|c|}{$\begin{array}{l}\text { Responders first } \\
\text { wave }(n=1106, \\
69.3 \%)\end{array}$} & \multicolumn{2}{|c|}{$\begin{array}{l}\text { Responders } \\
\text { second wave } \\
(n=822, \\
50.9 \%)\end{array}$} & \multicolumn{2}{|c|}{$\begin{array}{l}\text { Respond- } \\
\text { ers first and } \\
\text { second wave } \\
(n=696)\end{array}$} & \multicolumn{2}{|c|}{$\begin{array}{l}\text { Reference } \\
\text { population } \\
(n=241)\end{array}$} \\
\hline & & & & & & & & \\
\hline Age in years, mean (range) & 56 & $24-82$ & 57 & $29-83$ & 56 & $29-79$ & 58 & $31-82$ \\
\hline \multicolumn{9}{|l|}{ Sex, No. (\%) } \\
\hline Female & 1100 & 99.5 & 819 & 99.6 & 693 & 99.6 & 228 & 94.6 \\
\hline Male & 6 & 0.5 & 3 & 0.4 & 3 & 0.4 & 13 & 5.4 \\
\hline Body Mass Index ${ }^{\mathrm{a}}$, mean (SD) & 26.1 & 4.7 & 26.1 & 4.7 & 26.1 & 4.7 & 25.7 & 4.2 \\
\hline Missing, No. (\%) & 11 & 1.0 & 45 & 5.5 & 3 & 0.4 & 0 & 0.0 \\
\hline \multicolumn{9}{|l|}{ Highest educational level } \\
\hline Primary or (post-)secondary school & 488 & 44.1 & 339 & 41.2 & 293 & 42.1 & 98 & 40.7 \\
\hline College, graduate, or professional degree & 609 & 55.1 & 439 & 53.5 & 401 & 57.6 & 143 & 59.3 \\
\hline Unknown & 9 & 0.8 & 44 & 5.4 & 2 & 0.3 & 0 & 0.0 \\
\hline \multicolumn{9}{|l|}{ Current living situation } \\
\hline With partner and/or child(ren) & - & - & 647 & 78.8 & 554 & 79.6 & 190 & 78.9 \\
\hline Alone/other & - & - & 175 & 21.3 & 142 & 20.4 & 51 & 21.1 \\
\hline Follow-up time in months, median (range) & 29 & $1-78$ & 33 & $1-85$ & 31 & $1-78$ & - & - \\
\hline \multicolumn{9}{|l|}{ Tumor characteristics } \\
\hline \multicolumn{9}{|l|}{ Pathological T stadium, No. (\%) } \\
\hline $0+$ In situ (IS) & 173 & 15.6 & 121 & 14.7 & 112 & 16.1 & - & - \\
\hline I & 641 & 58.0 & 442 & 53.8 & 401 & 57.6 & - & - \\
\hline II-IV & 238 & 21.5 & 178 & 21.6 & 150 & 21.6 & - & - \\
\hline $\mathrm{X}+$ unknown & 54 & 4.9 & 81 & 9.9 & 33 & 4.7 & - & - \\
\hline \multicolumn{9}{|l|}{ Treatment characteristics } \\
\hline \multicolumn{9}{|l|}{ Type of breast surgery } \\
\hline Breast-conserving therapy & 863 & 78.0 & 619 & 75.3 & 555 & 79.7 & - & - \\
\hline Mastectomy \pm delayed reconstruction & 106 & 9.6 & 69 & 8.4 & 61 & 8.8 & - & - \\
\hline Mastectomy with direct breast reconstruction & 109 & 9.9 & 69 & 8.4 & 63 & 9.1 & - & - \\
\hline None & 20 & 1.8 & 14 & 1.7 & 12 & 1.7 & - & - \\
\hline Unknown & 8 & 0.7 & 51 & 6.2 & 5 & 0.7 & - & - \\
\hline \multicolumn{9}{|l|}{ Systemic therapy ${ }^{\mathrm{b}}$} \\
\hline No systemic therapy & 410 & 37.1 & 278 & 33.8 & 253 & 36.4 & - & - \\
\hline Chemotherapy & 100 & 9.0 & 77 & 9.4 & 71 & 10.2 & - & - \\
\hline Endocrine therapy & 201 & 18.2 & 155 & 18.9 & 135 & 19.4 & - & - \\
\hline Immunotherapy & 0 & 0.0 & 0 & 0.0 & 0 & 0.0 & - & - \\
\hline Combination of above ${ }^{\mathrm{c}}$ & 387 & 35.0 & 261 & 31.8 & 232 & 33.3 & - & - \\
\hline Unknown & 8 & 0.7 & 51 & 6.2 & 5 & 0.7 & - & - \\
\hline \multicolumn{9}{|l|}{ Radiation therapy } \\
\hline Yes & 993 & 89.8 & 702 & 85.4 & 631 & 90.7 & - & - \\
\hline None & 77 & 7.0 & 47 & 5.7 & 42 & 6.0 & - & - \\
\hline Unknown & 36 & 3.3 & 73 & 8.9 & 23 & 3.3 & - & - \\
\hline \multicolumn{9}{|l|}{ Currently receiving breast cancer treatment ${ }^{\mathrm{d}}$} \\
\hline Yes & 350 & 31.6 & 269 & 32.7 & 279 & 40.1 & - & - \\
\hline No & 756 & 68.4 & 553 & 67.3 & 417 & 59.9 & - & - \\
\hline
\end{tabular}

Baseline characteristics of the responders and non-responders of the first COVID-19 wave may differ from previously published results[8], as clinical data were routinely updated by the Netherlands Cancer Registry, and the number of responses to the first COVID-19-specific survey increased after analyzing the first responses (due to the timely subject, only responses received before April 24, 2020 were used for analyses in our previous publication[8])

As a result of rounding, percentages may not add up a $100 \%$

No number, $S D$ standard deviation

${ }^{\text {a }}$ Calculated as weight $/$ height $^{2}$

${ }^{\mathrm{b}} \mathrm{Pre}-\mathrm{and} /$ or post-operative therapy

${ }^{\mathrm{c} C}$ Combination of chemotherapy, endocrine therapy, and/or immunotherapy 
Table 1 (continued)

${ }^{\mathrm{d}}$ Active treatment is defined as receiving chemotherapy, endocrine therapy, immunotherapy, and/or radiation therapy at the time of completing the COVID-19-specific survey

$(n=350)$ received active breast cancer treatment at the time of completing the survey. During the second wave, the mean age of responders was 57 (range 29-83) years and median follow-up time since enrollment in the UMBRELLA cohort was 33 (range 1-85) months. The majority of the responders were treated for stage I breast cancer $(n=442,53.8 \%)$ and had undergone breast-conserving surgery $(n=619,75.3 \%)$. In total, $32.7 \%(n=269)$ of the responders were receiving active treatment for breast cancer at the time of completing the survey. During the second wave, demographic characteristics of the reference population were comparable to those of the responders. Demographic and clinical characteristics were similar between (non-)responders during the first and second wave (Supplementary Table 1).

\section{Perceived access to health care}

Of all patients, the proportion who felt a higher threshold to contact their general practitioner due to COVID-19 decreased from $29.9 \%(n=204)$ in the first wave to $20.8 \%$ $(n=145)$ in the second wave (Table 2). During the second wave, $16.2 \%(n=39)$ of the reference population felt a higher threshold to contact their general practitioner due to COVID-19. Lower barriers to contact their breast cancer physician(s) were experienced by $5.7 \%(n=40)$ of all patients when compared to the first wave and $7.5 \%(n=52)$ reported to still experience barriers to contact their breast cancer physicians during the second wave.

\section{Perceived impact on breast cancer care}

The proportion of patients who felt that their current treatment or follow-up care was affected by the COVID-19 pandemic decreased from $28.4 \%(n=198)$ in the first wave to $14.8 \%(n=103)$ in the second wave (Table 2). During the second wave, $42.3 \%(n=295)$ of all patients expected that their future treatment or follow-up care would possibly or surely be affected by the COVID-19 pandemic; this proportion was lower $(24.0 \%, n=167)$ in the first wave.

During the second wave, 23.1\% $(n=190)$ of all patients indicated that one or more hospital consultations were changed into a digital or telephone consultation and $10.0 \%(n=82)$ reported that at least one hospital consultation or breast cancer treatment was postponed (Table 3). Cancelation of one or more hospital consultations or breast cancer treatments was experienced by $1.1 \%(n=9)$ of patients. Overall, $61.7 \%(n=507)$ of all patients did not experience any effects on their breast cancer treatment or follow-up care during the pandemic.
Nearly half of all patients $(48.3 \%, n=396)$ indicated that digital medical and/or supportive care would be a useful alternative to in-person consultations. This was reported by $75.9 \%(n=183)$ of the reference population. In-person consultations remained most preferred in $35.2 \%(n=289)$ of all patients and $19.1 \%(n=46)$ of the reference population.

\section{Active versus no active breast cancer treatment}

During the second wave, $24.5 \%(n=66)$ of the patients receiving active treatment reported that their cancer treatment was affected due to COVID-19, and this was reported by $9.4 \%(n=52)$ of the patients who were not under active treatment and received follow-up care $(\mathrm{p}<0.001$, Table 4$)$. In $38.3 \%(n=103)$ of the patients receiving active treatment, one or more hospital consultations were changed into a digital or telephone consultation; this proportion was $15.7 \%(n=87)$ among patients only receiving follow-up care $(\mathrm{p}<0.001)$. One of more hospital consultations were postponed or canceled in $8.2 \%(n=30)$ of patients receiving active treatment and 9.4\% $(n=61)$ of patients receiving follow-up care. No changes in breast cancer treatment or follow-up care were reported by $46.1 \%(n=124)$ of the patients receiving active treatment and 69.3\% $(n=383)$ of the patients receiving follow-up care $(\mathrm{p}<0.001)$. The majority of the patients receiving active treatment $(58.4 \%, n=157)$ indicated that digital medical and/or supportive care would be a useful alternative to in-person consultations. This proportion was $43.2 \%(n=239)$ among patients only receiving follow-up care $(\mathrm{p}<0.001)$. In-person consultations remained most preferred in 27.9\% $(n=75)$ of patients receiving active treatment and $38.7 \%(n=214)$ of patients receiving follow-up care. No clinically relevant or statistically significant differences in perceived barriers in access to health care were observed between patients receiving active breast cancer treatment and patients receiving follow-up care during the second wave.

\section{Discussion}

The COVID-19 pandemic has had, and is still having, impact on health care seeking behavior and consumption in patients (being) treated for breast cancer. Fortunately, this study showed that perceived breast cancer care has recovered substantially nine months after the onset of the pandemic. The proportion of patients who felt a higher threshold to contact their general practitioner due to COVID-19 decreased from 29.9 to $20.8 \%$ during the pandemic. Also, the proportion of patients reporting that their cancer treatment or follow-up care was affected due to COVID-19 declined from 28.4 to 
Table 2 The impact of the COVID-19 pandemic on perceived access to health care in patients (being) treated for breast cancer ( $n=696$ ) compared to a reference population $(n=241)$ during the first and the second wave of the COVID-19 pandemic

\begin{tabular}{|c|c|c|}
\hline $\begin{array}{l}\text { First } \\
\text { wave }\end{array}$ & & $\begin{array}{l}\text { Second } \\
\text { wave }\end{array}$ \\
\hline $\begin{array}{l}\text { Respond- } \\
\text { ers } \\
(n=696)^{\mathrm{a}}\end{array}$ & $\begin{array}{l}\text { Respond- } \\
\text { ers } \\
(n=696)^{\mathrm{a}}\end{array}$ & $\begin{array}{l}\text { Reference } \\
\text { popula- } \\
\text { tion } \\
(n=241)\end{array}$ \\
\hline$\%$ & $\%$ & $\%$ \\
\hline
\end{tabular}

Did the threshold to contact your general practitioner change, because of the COVID-19 pandemic?

Yes, I contact my general practitioner more easily

$\begin{array}{llllll}13 & 1.9 & 6 & 0.9 & 4 & 1.7\end{array}$

Yes, I contact my general practitioner less easily

$\begin{array}{llllll}204 & 29.9 & 145 & 20.8 & 39 & 16.2\end{array}$

No, but during the first COVID-19 wave I contacted my general practitioner less easily

No

Did the threshold to contact the physicians treating your breast cancer change, because of the COVID-19 pandemic?

Yes, I contact my breast cancer physician(s) more easily

Yes, I contact my breast cancer physician(s) less easily

No, but during the first COVID-19 wave I contacted my physicians less easily

No

Did the threshold to discuss your breast cancer diagnosis or breast cancer (treatment)-related symptoms with family and friends change, because of the COVID-19 pandemic?

Yes, I contact my friends and family more easily

Yes, I contact my friends and family less easily

No, but during the first COVID-19 wave I contacted my family and friends less easily

No

Do the current COVID-19 measures affect your current breast cancer treatment or (after)care?

Yes

No

I don't know

Do you expect that the current COVID-19 measures will affect your breast cancer treatment or (after)care in the future?

Yes

No

I don't know

$\begin{array}{llllll}6 & 0.9 & 8 & 1.1 & - & -\end{array}$

$\begin{array}{llllll}100 & 14.4 & 52 & 7.5 & -\end{array}$

$-\quad-\quad 40 \quad 5.7 \quad-\quad-$

$59084.8596 \quad 85.6 \quad-\quad-$

\begin{tabular}{llllll}
9 & 1.3 & 9 & 1.3 & - & - \\
52 & 7.5 & 50 & 7.2 & - & - \\
- & - & 13 & 1.9 & - & - \\
635 & 91.2 & 624 & 89.7 & - & - \\
& & & & & \\
198 & 28.4 & 103 & 14.8 & - & - \\
498 & 71.6 & 546 & 78.4 & - & - \\
- & - & 47 & 6.8 & - & - \\
& & & & & \\
& & & & & \\
167 & 24.0 & 56 & 8.0 & - & - \\
529 & 76.0 & 401 & 57.6 & - & - \\
- & - & 239 & 34.3 & - & - \\
\hline
\end{tabular}

${ }^{a}$ All breast cancer patients $(n=696)$ completed both COVID-19-specific surveys during the first and second COVID-19 wave, i.e., in April 2020 and November 2020, respectively

$14.8 \%$. Almost a quarter (23.1\%) of all patients indicated that one or more hospital consultations were changed into a digital or telephone consultation. Nearly half of all patients $(48.3 \%)$ indicated that digital health care would be a useful alternative for in-person consultations.

During the first wave, COVID-19 had a major impact on the health care system in the Netherlands, among others, leading to a $25 \%$ reduction in general practitioner consultations [15]. In line with this, we observed that $29.9 \%$ $(n=204)$ of all patients (being) treated for breast cancer contacted their general practitioner less easily due to COVID-19 during the first wave. A cross-sectional Dutch study showed that $20.9 \%(n=852)$ of the cancer patients and $22.3 \%(n=218)$ of the matched norm population were less inclined to contact their general practitioner during the first month of the COVID-19 pandemic [7]. As a result of national campaigns aiming to improve equitable access to health care and adaptations of the health care system through the implementation of telehealth and extra hygiene safety precautions, perceived access to health care has improved over the course of the pandemic [16]. A study from Germany, where comparable government measures were implemented during the pandemic, observed that $13.2 \%(n=102)$ of the individuals requiring access to medical appointments experienced limited access to a general practitioner during the first wave in April 2020. This proportion decreased to 8.8\% $(n=76)$ during the second wave in December 2020 [17]. In the present study, the proportion of patients who 


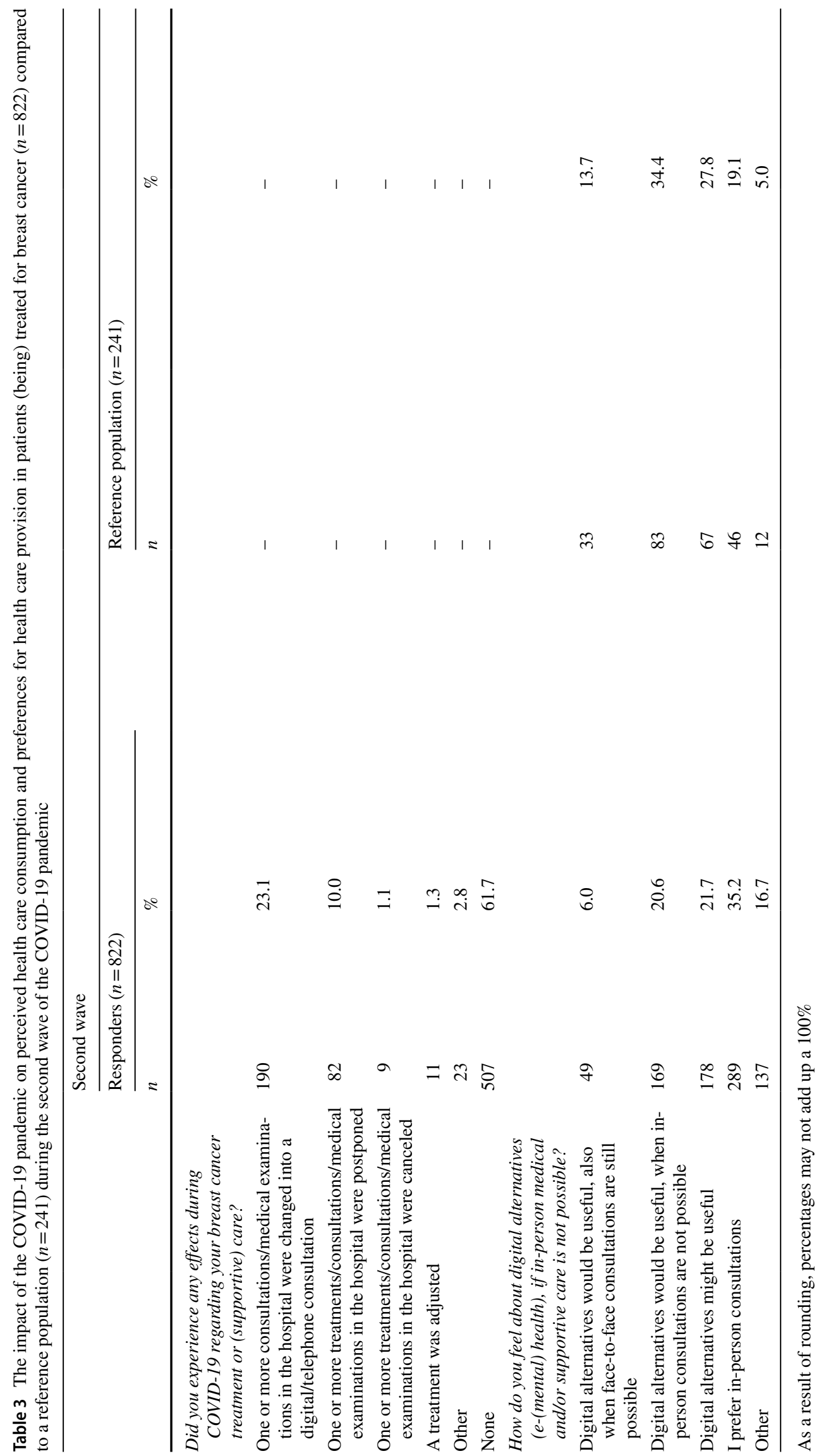


Table 4 The impact of the COVID-19 pandemic on perceived access to health care and preferences for health care provision in patients receiving active treatment and patients receiving follow-up care during the second wave of the COVID-19 pandemic

\begin{tabular}{|c|c|c|c|c|c|}
\hline & \multicolumn{2}{|c|}{$\begin{array}{l}\text { Active } \\
\text { treatment }^{\mathrm{a}} \\
(n=269, \\
32.7 \%)\end{array}$} & \multicolumn{2}{|c|}{$\begin{array}{l}\text { No active } \\
\text { treatment } \\
(n=553, \\
67.3 \%)\end{array}$} & \multirow[t]{2}{*}{ p-value } \\
\hline & $n$ & $\%$ & $n$ & $\%$ & \\
\hline Do the current COVID-19 measures affect your current treatment or (after)care? & & & & & $<0.001 *$ \\
\hline Yes & 66 & 24.5 & 52 & 9.4 & \\
\hline No & 193 & 71.7 & 460 & 83.2 & \\
\hline I don't know & 10 & 3.7 & 41 & 7.4 & \\
\hline Do you expect that the current COVID-19 measures will affect your treatment or (after)care in the future? & & & & & $0.231 *$ \\
\hline Yes & 43 & 7.8 & 22 & 8.2 & \\
\hline No & 334 & 60.4 & 146 & 54.3 & \\
\hline I don't know & 176 & 31.8 & 101 & 37.5 & \\
\hline $\begin{array}{l}\text { Did you experience any effects during COVID-19 regarding your breast cancer treatment or (supportive) } \\
\text { care? }\end{array}$ & & & & & $<0.001 * *$ \\
\hline $\begin{array}{l}\text { One or more consultations/medical examinations in the hospital were changed into a digital/telephone con- } \\
\text { sultation }\end{array}$ & 103 & 38.3 & 87 & 15.7 & \\
\hline One or more treatments/consultations/medical examinations in the hospital were postponed & 29 & 7.8 & 53 & 8.3 & \\
\hline One or more treatments/consultations/medical examinations in the hospital were canceled & 1 & 0.4 & 8 & 1.1 & \\
\hline A treatment was adjusted & 7 & 2.6 & 4 & 0.7 & \\
\hline Other & 5 & 1.9 & 18 & 3.3 & \\
\hline None & 124 & 46.1 & 383 & 69.3 & \\
\hline $\begin{array}{l}\text { How do you feel about digital alternatives (e.g., e-(mental) health), if in-person medical and/or supportive } \\
\text { care is not possible? }\end{array}$ & & & & & $<0.001 *$ \\
\hline Digital alternatives would be useful, also when in-person consultations are still possible & 25 & 9.3 & 24 & 4.3 & \\
\hline Digital alternatives would be useful, when in-person consultations are not possible & 64 & 23.8 & 105 & 19.0 & \\
\hline Digital alternatives might be useful & 68 & 25.3 & 110 & 19.9 & \\
\hline I prefer in-person consultations & 75 & 27.9 & 214 & 38.7 & \\
\hline Other & 37 & 13.8 & 100 & 18.1 & \\
\hline Did the threshold to contact your general practitioner change, because of the COVID-19 situation? & & & & & $0.290 * *$ \\
\hline Yes, I contact my general practitioner more easily & 0 & 0.0 & 7 & 1.3 & \\
\hline Yes, I contact my general practitioner less easily & 51 & 19.0 & 112 & 20.3 & \\
\hline No, but during the first wave of the COVID-19 pandemic I contacted my general practitioner less easily & 33 & 12.3 & 61 & 11.0 & \\
\hline No & 185 & 68.8 & 373 & 67.5 & \\
\hline $\begin{array}{l}\text { Did the threshold to contact the physicians treating your breast cancer change, because of the COVID-19 } \\
\text { situation? }\end{array}$ & & & & & $0.436^{* *}$ \\
\hline Yes, I contact my breast cancer physician(s) more easily & 4 & 1.5 & 6 & 1.1 & \\
\hline Yes, I contact my breast cancer physician(s) less easily & 24 & 8.9 & 42 & 7.6 & \\
\hline No, but during the first COVID-19 wave I contacted my physicians less easily & 19 & 7.1 & 27 & 4.9 & \\
\hline No & 222 & 82.5 & 478 & 86.4 & \\
\hline
\end{tabular}

As a result of rounding, percentages may not add up a 100\%: *Chi-squared test; **Fisher's exact test

${ }^{a}$ Active treatment is defined as receiving chemotherapy, endocrine therapy, immunotherapy, and/or radiation therapy at the time of completing the COVID-19-specific questionnaire during the second COVID-19 wave

felt higher barriers to contact their general practitioner due to COVID-19 decreased with $9.1 \%$ during the pandemic, despite persisting higher barriers to contact a general practitioner among $20.8 \%$ of the patients during the second wave. 
This modest improvement in health care seeking behavior suggests that individuals seem to slowly adjust to a crisis of this magnitude and lower their barriers in seeking health care.

Although improvements in perceived access to health care were observed, this study also shows that a substantial part of all patients and the reference population $(20.8 \%$ and $16.2 \%$, respectively) still experienced barriers to contact their general practitioner due to COVID-19 during the second wave. In line with this, Eijkelboom and colleagues observed a decrease in breast cancer incidences across all age groups during the first month of the COVID-19 pandemic in the Netherlands [4]. In addition to the halt of the Dutch national breast cancer screening program, the increased reluctance of patients to visit their general practitioner along with the advice to vulnerable individuals to stay at home in the first month of the pandemic might have contributed to this decrease in breast cancer incidence during the pandemic [6].

The COVID-19 pandemic has had consequences for cancer care, as a substantial part of cancer diagnoses and treatments worldwide were delayed or disrupted $[3,7,18,19]$. During the first month of the pandemic, a study assessing the impact of COVID-19 on breast cancer care in New York reported that $42.6 \%(n=149)$ of the patients experienced a cancer care delay and/or change [20]. In Australia, 42\% $(n=683)$ of cancer patients and survivors experienced disruption to their cancer care or treatment during the early months of the pandemic [21]. During the first two months of the COVID-19 outbreak, a Dutch survey among 5302 cancer patients showed that $30 \%$ experienced consequences for their treatment or follow-up care and 19\% reported being less inclined to contact the hospital [3]. Shortly after the first wave in the Netherlands, Van de Poll-Franse and colleagues observed that $10.8 \%(n=96)$ of all cancer treatments were postponed or canceled and $18.1 \%(n=160)$ of the consultations of patients receiving cancer treatment were changed into a telephone or video consultation [7]. This is comparable to our findings, in which $10.0 \%(n=82)$ of all patients indicated that at least one hospital consultation or breast cancer treatment was postponed and $23.1 \%(n=190)$ reported that one or more hospital consultations were changed into a digital or telephone consultation. Fortunately, despite the health care's challenges posed by the COVID-19 pandemic, only $1.1 \%(n=9)$ of all patients reported that one or more hospital consultations or treatments were canceled throughout the pandemic.

By means of adaptations in the health care system to minimize disruption of cancer care amid the current crisis, perceived cancer care seems to have recovered substantially. In the present study, the proportion of breast cancer patients experiencing that their current treatment or follow-up care was affected decreased from $28.4 \%$ in April 2020 to $14.4 \%$ in November 2020. This was also confirmed by the fact that only 7.5\% $(n=52)$ of all patients felt higher barriers to contact their breast cancer physicians during the second wave, whereas this was reported by $14.4 \%(n=100)$ in the first wave. As the proportion of patients receiving active treatment remained stable throughout the pandemic (i.e., 31.6\% during the first wave and $32.7 \%$ during the second wave), this improvement in perceived breast cancer care was not influenced by patients who completed their treatment during the pandemic.

In the light of the pandemic, rapid implementation of telehealth is now more important than ever. It facilitates and expands access to health care services and provides care to patients while minimizing the transmission risk of COVID-19 [22]. The rapidly increased demand for telehealth highlights both the potential value and the challenges of deploying telehealth, as a solution to provide health care during a crisis of this magnitude [23-25]. Although in-person consultations remained most preferred in one-third of the patients, it is promising that the increased use of telehealth in cancer care is well received by a substantial part (48.3\%) of the breast cancer patients in the present study, especially by patients under active treatment (58.4\%). Other studies also showed overall good patients' acceptance regarding the implementation and use of telehealth during the COVID-19 pandemic, among others, for reasons, such as travel time, travel expense, and convenience $[23,26]$. Especially cancer patients receiving active treatment seem to have adjusted quickly to the use of telehealth considering their overall satisfaction about their telehealth consultations [27-30]. An American study by Darcourt et al. found that $92.6 \%$ of all cancer patients $(n=1762)$ were satisfied with their telehealth consultations [31]. An international survey assessing the patients' perspective on telehealth during the first COVID-19 wave reported that $83 \%$ of all cancer patients with a virtual oncology appointment $(62 \%, n=129)$ was very satisfied with their experience [28]. In a cancer center-wide virtual care program, no changes in quality of care were observed among 22.085 (68.4\%) virtual consultations [29]. A total of $82 \%(n=2207)$ patients indicated overall satisfaction with virtualized care [29]. A study in France and Italy among 1244 breast cancer patients showed high levels of approval for telehealth visits during the COVID-19 pandemic [32]. Overall, our findings underline the relevance and support further acceptance of the implementation of telehealth as part of comprehensive cancer care.

A sudden rush, however, to digital care might diminish the quality of clinical care, i.e., in situations in which there is an inability to perform an adequate physical exam, a need to address sensitive topics, limited access to technological devices, low digital literacy, or a perceived ethical or security concern [24, 33-35]. In a large colorectal population in 
the Netherlands, $12.2 \%(n=379)$ of the patients indicated that their in-person visit was changed into a teleconsultation during the first month of the pandemic. Among those, an in-person consultation remained most preferred (70.4\%), also in patients receiving active treatment (80.7\%) [36]. In the current study, an in-person consultation remained most preferred in $35.2 \%$ of all patients. Therefore, future studies are needed to explore the long-term effects of telehealth on oncology care and QoL among cancer patients and survivors and focus on finding the right balance when implementing such adaptions in a sustainable manner.

The findings of the present study should be interpreted in the context of its limitations. First, 69.3\% $(n=1106)$ and $50.9 \%(n=822)$ of all breast cancer patients eligible responded to the COVID-19-specific survey during the first and second wave, respectively. Although patient demographics and clinical characteristics of responders were comparable to the non-responders, selective non-response may still be present and might have either over- or underestimated the results. Second, both COVID-19-specific surveys were sent to the UMBRELLA participants at two specific timepoints, i.e., during the peak of the first and second wave. The impact of the pandemic on perceived access to health care, health care consumption, and preferences for health care might have differed in between these peaks. As the number of newly reported COVID-19 infections temporarily decreased and governmental containment measures became less strict, the overall perceived burden of the COVID-19 pandemic was presumably lower. Last, data on COVID19-specific questions were not available before COVID-19, thus lacking the ability to compare the current results with pre-COVID-19 outcomes. A notable strength of this study is that the use of data from the large, prospective UMBRELLA breast cancer cohort provided the opportunity to compare the short- and long-term impact of the COVID-19 pandemic in an identical population of patients (being) treated for breast cancer $[8,10]$. This is the first long-term follow-up study monitoring perceived access to health care, preferences for health care provision, and health care consumption among breast cancer patients in the context of COVID-19. Moreover, a non-cancer reference population was included, allowing interpretation of the findings in relative to those of a general population suffering from a pandemic.

\section{Conclusion}

In conclusion, perceived breast cancer care has improved substantially in patients (being) treated for breast cancer between the first and the second wave of the COVID-19 pandemic. Digital health was well received during the pandemic, especially by patients receiving active treatment. This could be interpreted as a motivation to continue and improve digital cancer care even in the absence of a global pandemic.

Supplementary Information The online version contains supplementary material available at https://doi.org/10.1007/s10549-021-06458-3.

Acknowledgements None.

Author contributions The corresponding author (HMV) confirms that she had full access to all the data in the study and had final responsibility for the decision to submit for publication. All listed authors did not receive any writing assistance and have approved the manuscript before submission. Each author has contributed significantly to and is willing to take public responsibility for the following aspects of the study: Design: DRMM, CAB, MCTB, LES, IED, IOB, MFE, WM, MS, EJPS, TD, RB, AD, FL, DAY-A, and HMV. Data Acquisition: DRMM, CAB, MCTB, LES, and HMV. Analyses: DRMM, CAB, MCTB, FL, and HMV. Interpretation: DRMM, CAB, MCTB, FL, and HMV. Drafting: DRMM and CAB. Critical Revision: DRMM, CAB, MCTB, LES, IED, IOB, MFE, WM, MS, EJPS, TD, RB, AD, FL, DAY-A, and HMV.

Funding The authors received no financial support for the research (including study design; data collection, analysis, interpretation of data; and writing of the report), authorship, and/or (the decision to submit the article for) publication.

Availability of data and material Raw data were generated at the University Medical Center Utrecht. Derived data supporting the findings of this study are available from the corresponding author Prof Dr HM Verkooijen upon reasonable request.

Code availability Not applicable.

\section{Declarations}

Conflict of interest The authors have no conflicts of interest to disclose.

Ethical approval This study was in accordance with the ethical standards of the institutional and/or national research committee and with the 1964 Helsinki declaration and its later amendments or comparable ethical standards.

Consent to participate Informed consent from all individual participants was obtained within the UMBRELLA cohort.

Consent to publish Informed consent from all individual participants was obtained within the UMBRELLA cohort.

\section{References}

1. Borstkankervereniging (2020) Derde van de kankerpatiënten heeft last van de coronacrisis. https://www.borstkanker.nl/ nieuws/derde-van-de-kankerpatienten-heeft-last-van-de-coron acrisis. Accessed 3 Mar 2021

2. B-force (2020) Wat zijn jouw ervaringen met de gevolgen van de coronacrisis bij borstkanker of erfelijke aanleg? https://bforce. nl/wat-zijn-jouw-ervaringen-met-de-gevolgen-van-de-coron acrisis-bij-borstkanker-erfelijke-aanleg. Accessed 24 Feb 2021

3. de Joode K, Dumoulin DW, Engelen V et al (2020) Impact of the coronavirus disease 2019 pandemic on cancer treatment: 
the patients' perspective. Eur J Cancer 136:132-139. https:// doi.org/10.1016/j.ejca.2020.06.019

4. Eijkelboom AH, de Munck L, Lobbes MBI et al (2021) Impact of the suspension and restart of the Dutch breast cancer screening program on breast cancer incidence and stage during the COVID-19 pandemic. Prev Med 151:106602. https://doi.org/ 10.1016/j.ypmed.2021.106602

5. IKNL. COVID-19 en borstkanker. https://iknl.nl/covid-19/ covid-19-en-borstkanker. Accessed 19 Feb 2021

6. Eijkelboom AH, de Munck L, Vrancken Peeters MJTFD et al (2021) Impact of the COVID-19 pandemic on diagnosis, stage, and initial treatment of breast cancer in the Netherlands: a population-based study. J Hematol Oncol 14(1):64. https://doi.org/ 10.1186/s13045-021-01073-7

7. Van De Poll-Franse LV, De Rooij BH, Horevoorts NJE et al (2020) Perceived care and well-being of patients with cancer and matched norm participants in the COVID-19 crisis: results of a survey of participants in the Dutch PROFILES Registry. JAMA Oncol 7(2):279-284. https://doi.org/10.1001/jamaoncol. 2020.6093

8. Bargon CA, Batenburg MCT, van Stam LE et al (2021) Impact of the COVID-19 pandemic on patient-reported outcomes of breast cancer patients and survivors. JNCI Cancer Spectr 5(1):104. https://doi.org/10.1093/jncics/pkaa104

9. Nederlandse Federatie van Kankerpatienten organisaties (2020) Kankerzorg in de anderhalvemeter-samenleving: wat is jouw ervaring? https://nfk.nl/media/1/Downloads/201210-DJEcorona-II_rapportage_finaal.pdf (2020). Accessed 7 Nov 2021

10. CROW kennisplatform (2019) Gemiddelde afstand tot ziekenhuis. https://crow.databank.nl//jive? workspace_guid=561e9 d65-8dbc-4e68-b9fa-0ab10a596e8e. Accessed 1 Nov 2021

11. Borstkankervereniging (2020) Vandaag in het nieuws: Alle bevolkingsonderzoeken zijn weer opgestart. https://borstkanker.nl/ nieuws/vandaag-het-nieuws-alle-bevolkingsonderzoeken-zijnweer-opgestart. Accessed 3 Mar 2021

12. Young-Afat DA, van Gils CH, van den Bongard HJGD et al (2017) The Utrecht cohort for Multiple BREast cancer intervention studies and Long-term evaLuAtion (UMBRELLA): objectives, design, and baseline results. Breast Cancer Res Treat 164(2):445-450. https://doi.org/10.1007/s10549-017-4242-4

13. Gal R, Monninkhof EM, van Gils, et al (2019) The trials within cohorts design faced methodological advantages and disadvantages in the exercise oncology setting. J Clin Epidemiol 113:137-146. https://doi.org/10.1016/j.jclinepi.2019.05.017

14. Netherlands Cancer Registry (2020). www.cijfersoverkanker.nl. Accessed 22 Dec 2020

15. Heins $\mathrm{M}$ et al (2020) Impact coronapandemie op zorgvraag bij huisartsen (factsheet A). Nivel. Accessed 23 Feb 2021.

16. Pennell NA, Dillmon M, Levit LA et al (2021) American society of clinical oncology road to recovery report: learning from the covid-19 experience to improve clinical research and cancer care. J Clin Oncol 39(2):155-169. https://doi.org/10.1200/JCO. 20.02953

17. Reitzle L, Schmidt C, Färber F et al (2021) Perceived access to health care services and relevance of telemedicine during the COVID-19 pandemic in Germany. Int J Environ Res Public Health. https://doi.org/10.3390/ijerph18147661

18. Swainston J, Chapman B, Grunfeld EA et al (2020) COVID-19 lockdown and its adverse impact on psychological health in breast cancer. Front Psychol 11:2033. https://doi.org/10.3389/ fpsyg.2020.02033

19. Riera R, Bagattini AM, Pacheco RL et al (2021) Delays and disruptions in cancer health care due to COVID-19 pandemic: systematic review. JCO Glob Oncol 7:321-323. https://doi.org/ $10.1200 /$ go. 20.00639
20. Satish T, Raghunathan R, Prigoff JG et al (2021) Care delivery impact of the COVID-19 pandemic on breast cancer care. JCO Oncol Pract 17(8):e1215-e1224. https://doi.org/10.1200/op.20. 01062

21. Edge R, Meyers J, Tiernan G et al (2021) Cancer care disruption and reorganisation during the COVID-19 pandemic in Australia: a patient, carer and healthcare worker perspective. PLoS ONE 16(9):e0257420. https://doi.org/10.1371/journal.pone.0257420

22. Monaghesh E, Hajizadeh A (2020) The role of telehealth during COVID-19 outbreak: a systematic review based on current evidence. BMC Public Health 20(1):1193. https://doi.org/10. 1186/s12889-020-09301-4

23. McGrowder DA, Miller FG, Vaz K et al (2021) The utilization and benefits of telehealth services by health care professionals managing breast cancer patients during the COVID-19 pandemic. Healthcare 9(10):1401. https://doi.org/10.3390/healt hcare 9101401

24. Chan RJ, Crichton M, Crawford-Williams F et al (2021) The efficacy, challenges, and facilitators of telemedicine in posttreatment cancer survivorship care: an overview of systematic reviews. Ann Oncol S0923-7534(21):04464-04471. https://doi. org/10.1016/j.annonc.2021.09.001

25. Singh S, Fletcher GG, Yao X et al (2021) Virtual care in patients with cancer: a systematic review. Curr Oncol 28(5):3488-3506. https://doi.org/10.3390/curroncol28050301

26. Smrke A, Younger E, Wilson R et al (2020) Telemedicine during the COVID-19 pandemic: impact on care for rare cancers. JCO Glob Oncol 6:1046-1051. https://doi.org/10.1200/go.20. 00220

27. Chang PJ, Jay GM, Kalpakjian C et al (2021) Patient and provider-reported satisfaction of cancer rehabilitation telemedicine visits during the COVID-19 pandemic. PM R. https://doi.org/ 10.1002/pmrj.12552.10.1002/pmrj.12552

28. Loree JM, Dau H, Rebić N et al (2021) Virtual oncology appointments during the initial wave of the COVID-19 pandemic: an international survey of patient perspectives. Curr Oncol 28(1):671-677. https://doi.org/10.3390/curroncol280100 65

29. Berlin A, Lovas M, Truong $T$ et al (2021) Implementation and outcomes of virtual care across a tertiary cancer center during COVID-19. JAMA Oncol 7(4):597-602. https://doi.org/10.1001/ jamaoncol.2020.6982

30. Hasson SP, Waissengrin B, Shachar E et al (2021) Rapid implementation of telemedicine during the COVID-19 pandemic: perspectives and preferences of patients with cancer. Oncologist 26(4):e679-e685. https://doi.org/10.1002/onco.13676

31. Darcourt JG, Aparicio K, Dorsey PM et al (2021) Analysis of the implementation of telehealth visits for care of patients with cancer in Houston during the COVID-19 pandemic. JCO Oncol Pract 17(1):e36-e43. https://doi.org/10.1200/op.20.00572

32. Bizot A, Karimi M, Rassy E et al (2021) Multicenter evaluation of breast cancer patients' satisfaction and experience with oncology telemedicine visits during the COVID-19 pandemic. Br J Cancer. https://doi.org/10.1038/s41416-021-01555-y

33. Webster P (2020) Virtual health care in the era of COVID-19. Lancet 395(10231):1180-1181. https://doi.org/10.1016/S01406736(20)30818-7

34. Centers for Disease Control and Prevention (2020) Using Telehealth to expand access to essential health Services during the COVID-19 Pandemic. https://www.cdc.gov/coronavirus/2019ncov/hcp/telehealth.html. Accessed 5 May 2021

35. Dixit N, Van Sebille Y, Crawford GB et al (2021) Disparities in telehealth use: how should the supportive care community respond? Support Care Cancer. https://doi.org/10.1007/ s00520-021-06629-4 
36. Derksen JWG, May AM, van de Poll-Franse LV et al (2021) Colorectal cancer care and patients' perceptions before and during COVID-19: implications for subsequent SARS-CoV-2 infection waves. JNCI Cancer Spectr 5(4):47. https://doi.org/10.1093/ jncics/pkab047
Publisher's Note Springer Nature remains neutral with regard to jurisdictional claims in published maps and institutional affiliations.

\section{Authors and Affiliations}

Dieuwke R. Mink van der Molen ${ }^{1}$ (D) Claudia A. Bargon ${ }^{1,2} \cdot$ Marilot C. T. Batenburg $^{1} \cdot$ Lilianne E. van Stam ${ }^{1}$. Iris E. van Dam ${ }^{3}$. Inge O. Baas ${ }^{4}$ - Miranda F. Ernst ${ }^{5}$. Wiesje Maarse ${ }^{6} \cdot$ Maartje Sier $^{7}$. Ernst J. P. Schoenmaeckers ${ }^{8}$. Thijs van Dalen ${ }^{9} \cdot$ Rhodé M. Bijlsma $^{4} \cdot$ Annemiek Doeksen $^{2} \cdot$ Femke van der Leij $^{3} \cdot$ Danny A. Young-Afat $^{10}$. Helena M. Verkooijen ${ }^{1,11}$ on behalf of UMBRELLA study group

1 Division of Imaging and Oncology, University Medical Centre Utrecht, Heidelberglaan 100, 3584 CX Utrecht, The Netherlands

2 Department of Surgery, St. Antonius Hospital, Utrecht, The Netherlands

3 Department of Radiation Oncology, University Medical Centre Utrecht, Cancer Centre, Utrecht, The Netherlands

4 Department of Medical Oncology, University Medical Centre Utrecht, Cancer Centre, Utrecht, The Netherlands

5 Department of Surgery, Alexander Monro Clinics, Bilthoven, The Netherlands

6 Department of Plastic, Reconstructive and Hand Surgery, University Medical Centre Utrecht, Utrecht, The Netherlands
7 Department of Surgery, Rivierenland Hospital, Tiel, The Netherlands

8 Department of Surgery, Meander Medical Centre, Amersfoort, The Netherlands

9 Department of Surgery, Diakonessenhuis Utrecht, Utrecht, The Netherlands

10 Department of Plastic, Reconstructive and Hand Surgery, Amsterdam University Medical Centre, Amsterdam, The Netherlands

11 Utrecht University, Heidelberglaan, Utrecht, The Netherlands 